\title{
COSMOLOGIA LITERÁRIA DA VIOLÊNCIA: UMA LEITURA SOBRE A CONDIÇÃO PÓS-COLONIAL AFRICANA
}

\author{
Sebastião Marques Cardoso ${ }^{1}$
}

\begin{abstract}
Resumo: Neste artigo, pretendemos elaborar uma leitura crítica acerca da peça de teatro Orações de Mansata (2007), do escritor africano Abdulai Sila. Para isso, tomaremos a referida peça como texto literário, pois iremos evidenciar a expressão dos principais personagens relacionando-os com o contexto histórico-politico dos países africanos da pós-colonialidade, em especial Guiné-Bissau. A violência, um dos temas mais prementes da obra, é uma referência que permite traçar esse tipo de leitura. Acreditamos que o autor, diante da questão levantada por ele na peça, propõe um novo entendimento acerca dos efeitos da colonização e do pós-colonialismo em África.
\end{abstract}

Palavras-chave: Teoria Literária. Literatura Africana de Língua Portuguesa. Estudos Culturais e Pós-Colonialismo. Abdulai Sila.

Só o branco é que tem? Foi isso que Deus disse? Não, Deus disse que somos todos iguais, somos todos filhos d'Ele, com os mesmo direitos. E se é assim, porquê (sic) é que só o branco tem poderes no mundo?

Fala de Amambarka, personagem de Abdulai Sila (2007, p. 100)

Como não há literatura sem fuga ao real, e tentativas de transcendê-lo pela imaginação, os escritores [brasileiros] se sentiram frequentemente tolhidos no voo, prejudicados no exercício da fantasia pelo peso do sentimento de missão, que acarretava a obrigação tácita de descrever a realidade imediata, ou a exprimir determinados sentimentos de alcance geral.

Antonio Candido, a propósito da literatura brasileira (1997, p. 26)

Quando estamos diante da expressão literária de Abdulai Sila, ficamos estremecidos e perplexos. Difícil hoje uma literatura ser capaz de nos plantar no chão, de nos prender de tal forma através da situação vivida por seus principais personagens. A sensação de habitar um mundo enclausurado é, talvez, a maior e mais intrigante experiência que podemos encontrar na literatura desse escritor, natural de Guiné-Bissau. Esse incômodo pode ser percebido, por exemplo, na leitura de Orações de Mansata, peça de teatro do autor, publicada pela Kusimon Editora (Bissau), em 2007. Ao notar certa congenialidade com Macbeth, de William Shakespeare, Russel Hamilton (2007, p.7) afirma que a peça de Sila é a primeira escrita na Guiné-Bissau e também está no rol dos poucos textos dramáticos do pós-independência de toda a África.

Recentemente, através de um projeto apoiado pela União Europeia, a peça de Sila, dirigida por António Augusto Barros, teve 31 sessões apresentadas. Desde outubro de 2013, Orações de Mansata passou por Portugal, Espanha, Guiné Bissau e, de acordo com o projeto, finalizaria a tournée na cidade de Luanda, capital de Angola, em maio de 2014. Entretanto, o sucesso da peça é abruptamente interrompido quando o governo de Angola, através da Ministra da Cultura, interdita a apresentação da peça três horas antes

\footnotetext{
${ }^{1}$ Professor do Departamento de Letras e do Programa de Pós-graduação em Letras da Universidade do Estado do Rio Grande do Norte. E-mail: sebastiaomarques@uol.com.br.
} 
do espetáculo. Essa proibição, justificada pela falta de segurança do teatro, gerou muita decepção em toda companhia de teatro, bem como muitas desconfianças por parte do público local em relação aos motivos da suspensão do evento, pois a peça de Sila, sem indicar um país especificamente, toca em questões políticas caras às nações africanas pós-coloniais e ainda constrangedoras à classe dirigente desses países. Essa polêmica atesta, de maneira explícita, a atualidade e o engajamento do autor nas causas sociais e políticas através da literatura que produz.

Ora, a representação do espaço enclausurado, vivido intensamente pelos personagens de Sila na própria terra, decorre da existência de dois mundos bem distintos e delineados apontados no próprio texto:

[...] Reparem numa coisa: hoje é o branco que tem todos os poderes do mundo. Se precisarmos de viajar, temos que pedir ao branco, tem que ser com o carro ou o avião que o branco construiu; se precisarmos de construir casas grandes e bonitas tem que ser com modelos e materiais do branco; até falar com os nossos semelhantes agora só pode ser na língua do branco... Eles têm todos os poderes. (SILA, 2007, p. 99).

A partir da citação acima, notamos que o mundo dos brancos é visto pelos negros como espaço territorial, econômico, cultural e psicológico desenvolvido, e a ser imitado. As normas, regras, comportamentos e valores a serem seguidos são pautados por uma cultura invasora, que asfixia ou inibe as formulações culturais já existentes. Esse conjunto cultural ocidental, "atávico" na concepção de Édouard Glissant (cf. CARDOSO, 2014), conduz o sujeito local, o negro, a sentir-se estrangeiro na própria terra. Muitas vezes, essa sensação faz o negro sentir-se "minoria" quando se sabe maioria estatística.

Por outro lado, ao sentir-se agredido em seu próprio espaço, brota no negro o que Franz Fanon denomina "raiva vulcânica" (CABAÇO; CHAVES, 2004, p. 74). Esta é, depois, canalizada em variadas formas de expressão, como na dança, na música, no exorcismo e no transe, por exemplo. Porém, a ira por ser subalternizado no seu espaço e na sua subjetividade, leva o negro, nessas condições, a praticar sistematicamente a violência sobre seus iguais. Assim, reforça-se uma visão ocidentalista que o próprio negro a incorpora ao ver-se como força primitiva, violenta e psicologicamente não confiável. Essa situação, vale lembrar, não é um comportamento de percepção natural do negro. O que o branco (colonizador) construiu e no que o negro (colonizado) resultou são, em outras palavras, consequências de uma longa história de colonização (ou desumanização) e, depois, de um período intenso de lutas anticoloniais que, ao fim e ao cabo, tornaram as nações africanas independentes.

Portanto, quando falamos em colonizador/colonizado, estamos aludindo a um contexto específico que não pode ser generalizado. Porém, em função do problema apontado na peça de Sila, somos levados a pensar a questão do descolonizado - sob o pano de fundo histórico do conflito (ainda premente) entre colonizado vs colonizador como um assunto que nos poderá auxiliar na compreensão da difícil situação contemporânea vivida pelos países africanos que passaram por esse trágico processo em fins do século XX. A dominação colonial foi, nesses países, para além da alienação econômica. Ela atingiu de maneira dilacerante a própria humanidade dos autóctones, reduzindo-os a "elementos da natureza" (CABAÇO; CHAVES, 2004, p. 74). 
A violência - uns dos temas centrais da obra - é, a nosso ver, tributária das lutas de libertação. O colonizado conseguiu expulsar a presença física do colonizador através de um único programa, ou seja, do uso da violência absoluta: "Aquele a quem sempre se disse que ele só compreendia a linguagem da força decide expressar-se pela força. Efetivamente, desde sempre, o colono the mostrou o caminho que devia ser o seu, se quisesse libertar-se" (FANON, 2005, p. 102). Com a opressão do colonizador e, em consequência disso, a redução da subjetividade do colonizado, este último acabou por incorporar a inumanidade do próprio colonizador, que tanto temia. Nessa operação, toda a vida psicológica do colonizado foi transformada (deteriorada) à medida que a imagem construída do colonizador acerca do colonizado, em bases raciológicas, ia se naturalizando.

Com exceção de $A$ última tragédia (1995), a posição de Sila tem sido a de não fazer referência direta a seu país de origem. Pensamos que, com isso, o autor preocupase em tentar mostrar que aquilo que se passa em sua ficção não é um evento exclusivo à sua nação, mas algo que pode dizer respeito também a todo um conjunto de países africanos que viveu e ainda vive os dilemas expressos em sua literatura. Após a luta de libertação, tanto nos países lusófonos quanto francófonos, verificou-se a ascensão de elites autóctones diretamente envolvidas no movimento. Assim, líderes e excombatentes passaram a disputar, através de partidos, de alianças e de patentes militares cada vez mais a liderança política da nação.

O problema, diante disso, reside, a nosso ver, na incapacidade dessas elites em exorcizar o mal da cultura da violência que, em momentos anteriores, foi tão necessária para o recuo dos colonizadores. Seja pela ortodoxia ideológica, da hierarquia militar, da etnia ou da religião, os governos africanos pós-coloniais que assumiram o poder passaram não raro por um processo de canibalismo generalizado. Toda a suspeição e ira contra o colonizador fora canalizada contra seus próprios irmãos. Houve, assim, uma naturalização da violência nos meios sociais e políticos. Totalitarismo, traições e rebeliões passaram, então, a fazer parte da rotina das jovens nações africanas. Essa imagem do poder pós-colonial africano é vividamente traduzida na ficção de Sila.

Através da leitura crítica dos principais personagens construídos pelo escritor africano, percebemos mais que indícios de uma relação fortuita entre sociedade e cultura da violência. O principal temor do Supremo Chefe (presidente) é a sensação de que seu poder poderá a qualquer hora ser destituído por meio de uma conspiração. Mas esse temor, ou seja, esse receio tão grande que o perturba, o obriga a buscar os conselhos dos Homens-Grandes. Os Homens-Grandes são, em Guiné-Bissau, os chefes das tabancas - espécies de comunas africanas -, ligados profundamente aos valores místico-religiosos da etnia. Os Homens-Grandes indicam, como arautos, os caminhos da vida cotidiana por meio de conselhos hermeticamente espirituais. No caso específico do Supremo Chefe, busca-se, então, a proteção espiritual contra traições e, também, uma boa governação da nação.

A partir desse contexto, percebemos que a vida privada da elite de Guiné-Bissau guarda uma proximidade com as cenas retratadas no livro de Sila. O Supremo Chefe parece fazer alusão à política recente do país. Há uma figura bastante emblemática da história política de Guiné-Bissau que, por essa razão, faremos uma breve retomada. 
Trata-se de João Bernardo Vieira [1939-2009], mais conhecido como "Nino Vieira", excombatente do PAIGC (Partido Africano para a Independência de Guiné e Cabo Verde), ex-primeiro-ministro e ex-presidente bissau-guineense. É bom recordarmos que, no momento da publicação da peça de Sila (2007), Nino era o então presidente de GuinéBissau. Nino Vieira se filiou ao PAIGC na década de 60, participou como combatente na luta independentista contra os portugueses no período. Após a independência, ele foi, em 1978, nomeado primeiro-ministro do país.

Apesar de guerrilheiro e de formação mediana, Nino conseguiu paulatinamente atingir os postos mais altos na escala de poder. Em 1980, derruba, através de um golpe militar, o governo de Luís Cabral, e torna-se então o Chefe de Estado do país. E, em 1994, ele consegue novamente, agora por meio das urnas, a presidência do país, redimindo, assim, sobretudo aos olhos internacionais, a sua cumplicidade em intentonas e pressões militares. Porém, um conjunto de insatisfações em relação à sua conduta política (e militar), bem como o agravamento das tensões sociais e econômicas no país, empurraram Nino para uma guerra civil na qual saiu vencido. Em 1999, os rebeldes depõem Nino, que vai para o exílio. Contudo, mais tarde, voltando do exílio, Nino ainda vence as eleições em 2005, tornando-se outra vez presidente do país.

Em resumo, ex-guerrilheiro, ex-primeiro-ministro e três vezes presidente do país, Nino encerra sua odisseia política em 2009 de maneira trágica. Na sequência de um golpe contra o chefe das forças armadas do país, Nino foi brutalmente assassinado num (contra)golpe que, desta vez, não foi possível esconder-se ou exilar-se em tempo. A história de Nino é uma história que chama a atenção para o fato de como que, por tanto tempo, ele conseguiu manter-se na frente política do país, e livrar-se não só uma vez de várias escaramuças feitas contra ele. E, por outro lado, de como ele usou a astúcia e o poder para liquidar vários focos de resistência a seus planos políticos.

No texto de Sila, há uma trama similar às convulsões políticas africanas, cujo paradigma guarda similaridade com a condução política dos países terceiro-mundistas e pós-coloniais do mundo todo. O presidente, na peça de Sila, aparece cercado de conselheiros (ministros) e com uma dificuldade enorme em governar. Esse presidente sofre com pressões internas e externas: "O meu dinheiro roubado na Europa [congelado], os meus rendimentos cada dia mais reduzidos, a oposição cada dia mais activa e agressiva..." (SILA, 2007, p. 29). A situação do presidente parece indicar um roteiro maquiavélico do percurso das nações pós-coloniais e terceiro-mundistas.

Quando as aspirações populares não são alcançadas e, além disso, os organismos internacionais conspiram para a troca de governo, as tensões sociais e ideológicas instauradas abrem espaço para a violência interna estimulada tanto pelo próprio mandatário do país (na tentativa de preservar o seu poder), quanto pela iniciativa da oposição e/ou pelos próprios homens de confiança do governo que, ao conspirar, notam logo a possível vantagem política diante de um cenário meticulosamente confuso. Desse modo, verifica-se um clima de violência (psicológica e ameaças físicas) cada vez mais intenso que, num momento próximo, culmina em atos de perseguição (prisões, sequestros e execuções) por parte do governo e/ou, por outro lado, em conspirações cada vez mais ortodoxas e, portanto, mais violentas e espetaculares. Assim, a maior preocupação do presidente consiste em antecipar-se à sua derrocada e identificar os possíveis traidores antes que eles executem os planos. 
O presidente, personagem de Sila, procura, então, compreender a situação política que o pressiona cada vez mais, na tentativa de reverter o quadro político em seu favor. Nesse processo, ele procura, também, identificar toda a gente que conspira contra ele. E um dos elementos desestabilizadores é, para ele, a conspiração dos "brancos". O presidente, apesar de ditador, gozava de todas as regalias de um chefe de estado no mundo ocidental, mas, agora, vê-se perseguido por sanções econômicas e por apoios explícitos à mudança de regime: "Vocês sabem dos problemas com que me deparo neste momento, de há uns tempos a esta parte, desde que os brancos vieram com estas manias de eleições e democracias e internets e não sei que mais. Isso só veio a complicar a situação da nossa querida nação" (SILA, 2007, p. 32). Através do trecho acima, percebemos com clareza a inusitada conjectura política que enredou o presidente da nação: antes, um cliente europeu (mesmo sendo um ditador), com contas e pompas de chefe de estado, agora um pária político, com contas bloqueadas, acessos negados e figura política a ser combatida e substituída (não importando os meios para isso).

O presidente, representado por Sila, pagou, assim, por sua aliança com o Ocidente, e a estratégia do Ocidente para retomar sua força colonialista na ex-colônia fora justamente o desenvolvimento de um duplo padrão nas relações políticas. Isso posto, o presidente se sentiu traído pelo Ocidente. Antes, revolucionário africano ou ditador "bom" de partido único, agora um representante da nação caçado como bandido internacional, cheio de transgressões aos direitos humanos.

Para obter vínculos e parcerias estratégicas, o Ocidente, mesmo mantendo uma retórica eurocêntrica universalista, associou-se ao presidente africano. Na medida em que os vínculos (políticos, econômicos, sociais e culturais) iam se alargando cada vez mais dentro do espaço da nação africana, as exigências ocidentais ao líder da nação se tornavam também cada vez mais austeras, e, de repente, a política da nação já não era mais soberana, mesmo tendo como figura simbólica um partido de retórica estadista. Enfim, notamos que a primeira "traição", e talvez a mais decisiva, que ocorre na peça de Sila, é a do Ocidente em relação ao presidente africano ou, em outros termos, do presidente em relação ao Ocidente, pois ele não dá conta de cumprir todas as exigências feitas a ele. A partir desse conflito, uma série de outras tensões se sucede.

A herança do colonialismo não foi totalmente esvaziada na pós-colonialidade (cf. SAID, 2011). Assim como nos demais países africanos, Guiné-Bissau conquistou a independência por meio de armas, mas, na vida política e, sobretudo, em áreas como ciência, tecnologia, economia e cultura (produção intelectual e educação), continuou a depender das organizações ocidentais. O processo de descolonização dessas áreas está ainda por se fazer. Como vimos, Nino Vieira esteve, na primeira fase, ou seja, no tempo das lutas independentistas, em oposição aos projetos do Ocidente. Mas, passado esse período, toda a conjectura política a favor de uma nova nação soberana foi paulatinamente absorvida por forças colonizadoras (Portugal novamente e França) já conhecidas pelas nações africanas. Por que ocorre essa virada na política desse país africano? Como pode um presidente ex-combatente, momentos depois, ser apoiado por forças colonizadoras? Infelizmente, sabemos do desfecho disso tudo. Nino Vieira, após a independência do país, conscientemente ou não, decidiu compartilhar a guarda das ovelhas com os velhos lobos. O país voltou-se para o Ocidente e tornou-se um objeto de 
disputa entre velhas nações e nações emergentes. Resultado: a nação pós-colonial africana mergulha num conflito de identidade já profundamente abalado pelo processo de independência política, e passa a viver um ciclo de insegurança e de violência por conta desse impasse.

Em geral, após o esplendor das revoluções africanas, líderes são assassinados, golpes são perpetrados e, em pouco tempo, as nações colonizadoras começam explicitamente a indicar (e impor) os modelos políticos, econômicos e sociais a serem seguidos novamente. Cada nação africana tem sua complexidade interna, mas, quando tomamos o continente em perspectiva, perceberemos que o Ocidente voltou a administrar muitas áreas africanas (nações), porque essas áreas perderem o apoio, em todos os setores (militar, econômico, tecnológico e cultural), das nações não alinhadas ao Ocidente. A unipolaridade do sistema do capitalismo global se impôs. Ora, isso deixou as jovens nações africanas recém-libertas à deriva, obrigando-as a submeteremse novamente, ainda que em novas bases, à hegemonia do Ocidente. Essa situação, assimétrica por sua vez, gerou, e ainda gera, descontentamento em ambas as partes: do ponto de vista do Ocidente, espera-se "mais democracia" e "segurança", e do ponto de vista dos africanos, a revolução ainda não acabou, pois suas riquezas continuam sendo saqueadas e a melhoria social não atinge todo o conjunto da sociedade.

Como estamos vendo, o presidente representado por Sila evoca o contexto histórico da África e, não por acaso, o de Guiné-Bissau. O país entrou na póscolonialidade, tendo um quadro remanescente do tempo da colonização: analfabetismo, condições sanitárias precárias, instituições econômicas fracas, aparelho de estado ineficiente e quadros profissionais inexistentes. Esse atraso, longe de ser vencido ao longo do tempo, levou a nova classe dirigente do país a estratégias muito contraditórias. Quando uma sociedade não dispõe de recursos mínimos humanos preparados, e diante de um cenário cujas instituições não garantem o bem estar da população (educação, saúde, trabalho, previdência social etc.), o próprio Estado começa a aproveitar-se dessa situação, agindo como polícia para aplacar as tensões sociais. Com isso, o Estado subalterniza ainda mais seus próprios cidadãos.

Impedidos legalmente de se auto representarem na política, de terem os mesmos direitos à voz no espaço social dominante, a subalternização dos cidadãos se aprofunda, chegando às raias da eliminação física dos indivíduos ou grupos subalternizados. Ignorar esse fato, ou seja, a subalternização dos indivíduos é, de acordo com Spivak (2010, p. 97), continuar o projeto imperialista. E essa subalternização se dá em várias escalas, mas é no espaço pós-colonial que podemos notar sua dimensão mais totalitária e mais crua. Nesses espaços, a violência sobre os subalternos é, para a lógica do Estado, o único recurso repressor que poderá manter o seu status quo. Com isso, os estados africanos sob essa égide funcionam como "feitores" renovados das nações estrangeiras de vocação imperial. As novas elites africanas fazem o "trabalho sujo" para elas.

Ora, diante de tantos apuros, prestes a perder o poder, o presidente retratado por Sila recorre aos Homens-Grandes. Com essa atitude fica bastante clara a condição póscolonial do chefe da nação. Quando um presidente de um país ocidental está sob pressão, geralmente recorre aos próprios organismos europeus ou americanos de apoio (ONU, CEDEAO, OTAN e outros aparelhos globais e de Estado já consolidados). No 
caso africano, onde o presidente não está completamente alinhado à política do Ocidente, não há mecanismos internos de Estado consolidados, e os organismos com os quais mantém disputas são justamente os organismos internacionais de constituição europeia ou anglo-saxã.

Isso posto, a assimetria de poder é flagrante, e, além disso, o governante, remanescente da luta armada, não se caracteriza como um político orgânico de formação, como costuma ocorrer nos países desenvolvidos. A ideologia do presidente é a de um combatente militar, que conseguiu atingir o grau político mais elevado dentro da nação, tendo, sobretudo, a força militar como principal condição de domínio e de coerção. Então, ocupar uma zona central de poder político não é, para um líder ou chefe de Estado africano, uma condição simplesmente natural, pois condicionantes internas quanto externas não favorecem a estabilidade e o desenvolvimento de estruturas sociais mais plenas e sólidas. Nesse jogo, avulta a perspectiva mística como forma de blindagem e de garantia de continuidade de poder. O que vemos no presidente de Sila é magistralmente isso, ele recorre ao místico porque de outra maneira, ou seja, pelos meios racionais, as possibilidades não lhe são favoráveis.

O presidente quer saber, pelos Homens-Grandes, quais são os espíritos malignos que "estão a tentar semear desgraça e anarquia" (SILA, 2007, p. 33) no país. Antes de fazer a revelação, os Homens-Grandes lembram o presidente de que seu governo foi construído com muita violência e que, por isso, tem uma dívida a pagar: "[...] fizeste chorar muita gente nesta terra, gente que mesmo querendo, não te vai poder perdoar" (SILA, 2007, p. 34). A revelação é a de que o presidente, mesmo fazendo uso da força, não nasceu para ser o verdadeiro chefe da nação: "Não tens poder no sangue" (SILA, 2007, p. 34). Com isso, percebemos que o presidente, retratado por Sila, sofre uma dupla condenação: ele é abandonado pelos neocolonizadores, grandes fomentadores e apoiadores da oposição interna, e também pela própria sabedoria mística do país, que funciona como uma espécie de instituição, para além de religiosa, moral e ética da nação.

O presidente confessa aos Homens-Grandes que o país que governa é uma nação de traidores: "A sensação de estar a ser traído enerva-me, faz-me sentir mal, muito mal..." (SILA, 2007, p. 35). Após esse desabafo, os Homens-Grandes profetizam a chegada de um líder e que, por isso, o presidente devia localizá-lo e tê-lo perto de si, só assim poderia então obter sua redenção, ou seja, expirar-se dos males que fez. Contudo, um de seus conselheiros, ao ouvir a revelação, tenta encontrar esse líder antes que ele, mas logo é descoberto pelo presidente. Porém, o conselheiro percebe que foi descoberto e, então, resolve assaltar a presidência. Assim, o conselheiro, através da ajuda de homens armados de sua confiança, mata o presidente e assume o poder.

A maldição do presidente africano passa agora às mãos do novo chefe da nação, o ex-conselheiro do governo. O novo presidente - passaremos a chamá-lo assim a partir de agora - tem igualmente um passado que o acusa, como murmura um fantasma: "Vite naquela noite, vi o teu rosto quando a tua gente descarregou cartucheiras no meu peito" (SILA, 2007, p. 54). E, na mesma pegada do presidente morto, o novo presidente imagina resolver o problema da nação e de sua particular proteção. Com o corpo fechado, quer governar. Mas, para isso, precisa encontrar o "redentor" da nação de que 
falaram os videntes. Assim, desenha-se um novo mapa de violência cuja interpretação parece fugir da compreensão histórica dos fatos. Uma crença sobre governo e segurança é instituída, tendo a própria troca de presidente ou de governo associada à ela.

Nesse sentido, vemos na peça de Sila dois mundos de órbitas distintas, mas que, num nível mais profundo, se cruzam e se misturam. Há o sentido histórico que explica e ajuda a compreender os dilemas vividos pelos presidentes africanos, na esfera geopolítica da pós-colonialidade; e, por outro lado, uma medida espiritual que foi traída, mas que se manifesta incondicionalmente na moral e ética dos governantes com explícitas acusações e sanções. A mensagem espiritual é a de que somente um governante de mãos limpas poderá tirar a nação do sufrágio. E esse governante está por vir, pois é esse o vaticínio dado pelos Homens-Grandes.

O novo presidente logo descobre que, na verdade, o que o torna imune no poder são as orações de uma mulher conhecida como Mansata. Traçando um paralelo com a imaginação sobre a história política recente de Guiné-Bissau, os populares do país acreditavam que Nino Vieira tinha, de fato, um corpo fechado, imune à bala, por exemplo. Quando este foi morto, contavam-se entre os cidadãos que, para matá-lo, foram utilizados facões com cabos feitos com "pau de feiticeiro", pois, desta sorte, os assassinos acreditavam que só com armas assim, com o poder dos feitiços, poderiam quebrar o encanto do presidente, dando cabo, então, à sua imortalidade.

Ainda sobre os hábitos socioculturais de Guiné-Bissau, o homem, na vida amorosa, pode ter mais de uma namorada ou esposa. Por isso, os homens de maior poder político ou prestígio social ostentam sua riqueza ou notoriedade através de suas mulheres. Um dos personagens centrais de Orações de Mansata faz a seguinte revelação: "Eu serei o Supremo Chefe e terei os carros que quiser, as casas que quiser e mulheres! Terei mulheres, muitas mulheres, as mulheres mais lindas... Mulheres dóceis e submissas, mulheres que serão só minhas, só minhas, todo o tempo, todos os dias... Mulheres submissas! Terei várias casas e em cada casa uma mulher!” (SILA, 2007, p. 71). Com isso, percebemos a ambição do personagem, que busca a presidência para ter prestígio social.

No texto de Sila, não por acaso, há outras referências acerca das mulheres. Seus perfis são complexos, abrangendo desde uma "segunda Primeira Dama", a exigir tratamento de Primeira Dama, passando por mulher vulgar, universitária e independente. Elas, inclusive, dialogam com a figura do presidente e de seu conselheiro. Muitas vezes, antes de elas serem vistas apenas como gênero submisso, cobram de seu esposo as promessas de distinção, conforto e riqueza feitas a elas. Essas mulheres podem, ainda, abandoná-lo se suas expectativas não forem satisfeitas. Apesar de corajosas, a violência sobre as mulheres retratadas por Sila é também flagrante. Desse modo, poderíamos afirmar que tanto na esfera política quanto no meio doméstico a violência está bastante presente no país africano descrito pelo autor. A violência é, pois, uma condição resiliente que paira sobre a nação pós-colonial. E Sila denuncia esse estado de absoluta tensão através de sua ficção.

Das mulheres que aparecem ou são citadas no texto de Sila, com certeza, Mansata é a mais enigmática. Sua voz, ao contrário da situação geral da mulher na póscolonialidade - gênero encurralado entre modernidade e tradição (SPIVAK, 2010) - é 
venerada. A atmosfera de machismo que paira no livro se rende diante da força cósmica da personagem. Toda a proteção espiritual, bem como todo o poder necessário para governar, têm como fonte as palavras/orações dessa mulher. Mas aquilo que poderia constituir uma dádiva ao chefe da nação é, também, fonte de disputas e novas violências. A alusão à Mansata, uma sacerdotisa africana misteriosa, vai muito além de uma pura referência. Essa alusão à personagem mostra muito bem que para o país sair da cultura da violência é preciso, antes, e de acordo com um dos videntes que aparece no livro, retomar a "harmonia e benevolência" dos antepassados.

A colonização e, depois, a pós-colonialidade abriram uma fissura entre a classe política do país e a sua própria tradição. O que Sila sugere, em seu texto, é justamente a tomada de consciência de que para avançar a classe dirigente precisa abandonar a violência sobre si mesma e se reaproximar do esoterismo africano como forma de purificação do próprio espírito. Não se trata, como pensaram os chefes de Estado representados no livro, de simplesmente se apoderar das orações, imaginando que elas, por si só, poderiam dar-lhes o poder para fazer progredir a nação. Com isso, Sila propõe uma saída crioula para a situação: recuperar a tradição (antiguidade cultural) por meio de uma nova juventude.

Essa é a figura do "redentor", do presidente que ainda não é, do presidente-em-sefazendo, que aparece no primeiro ato do texto de Sila. Esse personagem é um ícone do homem mestiço, pois tem formação no exterior, mas ainda guarda a sensibilidade/passado de todo o povo da nação. A nova figura imaginada por Sila é esse sujeito antigo e jovem ao mesmo tempo, ou seja, alguém que marca presença no mundo, consciente de que o espaço de hoje é um entroncamento de culturas parceiras e rivais, compósitas e atávicas, cuja convivência é conflituosa e híbrida, mas que pode ser, através de relações horizontais, também harmônica na busca de soluções e no reconhecimento da opressão.

A questão que se coloca, agora em Sila, não é mais sonhar um mundo, mas, sim, vivê-lo. A beleza, evocando Glissant (1997, p. 221), não vem de um sonho, mas da imprevisibilidade da grande explosão da mistura. Desse modo, o personagem proposto por Sila é um sujeito que vai além de uma arquitetura de uma política redentora para o país africano, ele é também uma nova referência ao mundo: "Nous combattons les oppressions en notre lieu, nous ouvrons aussi sur les îles voisines, et sur toutes les terres" (GLISSANT, 1997, p. 230). ["Nós combatemos as opressões em nosso próprio espaço, nós nos abrimos também sobre as ilhas vizinhas, e sobre todas as terras"]. ${ }^{2} \mathrm{~A}$ batalha do futuro líder imaginado por Sila é, inclusive, farol para a libertação de outros povos.

Nessa perspectiva, a fórmula, assim, para sair do simulacro pós-colonial da violência ou da condição terceiro-mundista requer despir-se da imagem de si elaborada por outrem, que faz com que as ações na vida prática neguem a ética e os valores mais nobres dos autóctones em favor de uma mímica do comportamento espelhado no simplesmente outro. Na vida política, Sila indica que o indivíduo - negro, africano e subalternizado em sua própria terra - necessita tomar consciência de sua condição pós-

\footnotetext{
${ }^{2}$ A tradução cotejada do francês para o português foi, nesse texto, elaborada pelo próprio pesquisador.
} 
colonial ambígua, libertando-se dos embustes da mentalidade de seus governantes vítimas históricas e psicológicas do Ocidente - que progressivamente fracassam ao reproduzir um comportamento fomentado e induzido por agentes externos. Essa distorção os torna caricatos, mímicos e imensamente longe da realidade do imaginário da sua própria nação. Em resumo, um governo africano cativo em sua própria terra está inexoravelmente condenado à ruína, à insolvência e à violência irrestrita, levando consigo toda a nação. Sem unidade, ou seja, sem engajamento social através de comunidades, esse governo, ao fim e ao cabo, representa confusamente somente si mesmo, cujo discurso reverbera aspirações totalitárias em face dos receios iminentes de uma conspiração.

\section{CONSIDERAÇÕES FINAIS}

Depois desse percurso sobre a ficção de Sila, podemos tirar, mesmo que provisoriamente, algumas conclusões. Sila inicia uma cultura dramatúrgica em seu país, demonstrando desde já um engajamento estético-político bastante evidente. Entendemos que a opção do escritor por uma peça de teatro não só diversificou as estratégias literárias cultivadas como também fez com que o autor se aproximasse ainda mais de seu público. Desse modo, esperamos que, através do teatro, Sila possa levar sua mensagem ao público de maneira mais eficaz e para um maior número de receptores. Por outro lado, sua peça, em face da riqueza artística, pode ser também lida como texto literário. Foi por esse viés que abordamos o seu texto.

No domínio da representação da imaginação, Sila revela a medida da desmedida do caos-mundo vivida por sujeitos pós-coloniais construídos na atmosfera da violência refratária do tempo da colonização. Esses sujeitos são a negação de uma ordem que não se encaixa mais no mundo sistêmico-ocidental e tampouco se encaixa na ordem do mundo cultural africano. São seres desconexos ou quase autómatos que fazem da violência a sua principal marca. Sila, ao elucidar essa esquizofrenia do poder em África, mostra também um caminho alternativo a trilhar. Será no seio da desmedida, entre a razão neocolonial e a resistência africana, descolonial, que surgirá uma nova medida como forma de organização do poder e de controle sobre o imaginário político, cultural e social. Enfim, Sila propõe, contra o enclausuramento da nação e de seus indivíduos, a abertura das compotas da opressão ao mundo, às ilhas vizinhas, como forma terapêutica de sanar as próprias dores e de, pois ainda há tempo, corrigir os rumos da nação.

Entretanto, aludindo à epígrafe de Antonio Candido, destacada no início desse texto, de que a literatura é, sobretudo, transcendência à realidade imediata, notamos que a peça de Sila, ao prender-se diretamente na crítica do aparelho do Estado africano póscolonial, traça um voo imaginativo de médio alcance. A missão de corrigir, através da mensagem veiculada, os rumos da nação, acaba por determinar e tolher significativamente a imaginação plena do autor. Mesmo assim, a expressão da peça é característica e seminal e, com certeza, terá desdobramentos no espaço das produções culturais e literárias africanas de língua portuguesa. A literatura de Sila, em outras palavras, é empenhada e necessária em função do estágio em que as letras se encontram no país e das condições sociais e econômicas do próprio meio. 
CABAÇO, J. L; CHAVES, R. Frantz Fanon, colonialismo, violência e identidade cultural. In: ABDALA JUNIOR, B. (org). Margens da cultura. Mestiçagem, hibridismo \& outras misturas. São Paulo: Boitempo, 2004.

CANDIDO, A. Introdução. In: Formação da literatura brasileira: momentos decisivos. Belo Horizonte-Rio de Janeiro: Editora Itatiaia Limitada, 1997, p. 23-37, vol. I.

CARDOSO, S. M. Dicionário da crioulização. In: Poéticas da mestiçagem: textos sobre culturas literárias e crítica cultural. Curitiba: Editora CRV, 2014.

FANON, F. Os condenados da terra. Trad.: Enilce A. Rocha, Lucy Magalhães. Juiz de Fora: Ed. UFJF, 2005.

GLISSANT, É. Traité du Tout-Monde. Poétique IV. Paris: Gallimard, 1997.

HAMILTON, R. G. Prefácio. In: SILA, A. As orações de Mansata. Bissau: Ku Si Mon Editora, 2007.

SAID, E. W. Cultura e imperialismo. Trad.: Denise Bottmann. São Paulo: Companhia das Letras, 2011. SILA, A. As orações de Mansata. Bissau: Ku Si Mon Editora, 2007.

A última tragédia. Bissau: Ku Si Mon Editora, 1995.

SPIVAK, G. C. Pode o subalterno falar? Trad.: Sandra R. G. de Andrade, Marcos P. Feitosa, André P. Feitosa. Belo Horizonte: Editora UFMG, 2010.

\section{Recebido em 22/09/2014. Aprovado em 08/11/2014.}

Titre: Cosmologie littéraire de la violence: une lecture sur la condition postcoloniale africaine

Résumé: Dans cet article, nous voulons élaborer une lecture critique sur la pièce théâtrale Orações de Mansata (2007), de l'écrivain africain Abdulai Sila. Par conséquent, nous voulons voir cette pièce comme aussi un texte littéraire, où nous irons mettre en évidence l'expression des personnages principaux à côté du contexte historique et politique des pays africains de la postcolonialité, spécialement Guiné-Bissau. La violence, un thème plus recourent présent dans la pièce, est une référence qui va nous permettre d'inscrire cette sorte de lecture. Nous croyons que l'auteur nous montre une nouvelle raison de comprendre les effets de la colonisation et du postcolonialisme en Afrique.

Mots-clés: Théorie Littéraire. Études Culturelles et Postcolonialisme. Littérature Africaine de Langue Portugaise. Abdulai Sila. 
